Metal-Mediated Synthesis

\section{Mn-Catalyzed Cross-Coupling of Aryl Grignard Reagents with Alkenyl Halides}

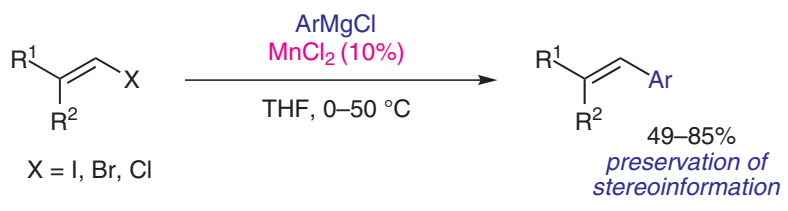

Examples:<smiles>COc1ccc(/C=C/c2ccccc2)cc1</smiles>

$65 \%$

$E / Z=96: 4$

(starting material $E>99 \%$ )<smiles>COc1ccccc1/C=C\c1ccccc1</smiles>

$79 \%$ (starting material $Z>99 \%$ )

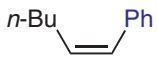

EI $75 \%$

$E / Z=99: 1$

(starting material $E / Z=99: 1$ )

starting material $E / Z=1: 99$ )

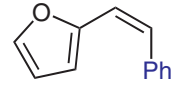

$55 \%$

$E / Z=4: 96$

(starting material $Z>99 \%$ )
Key words

manganese

catalysis

cross-coupling

stereoselectivity

aryl Grignard

reagents

alkenyl halides (starting material $E>99 \%$ )

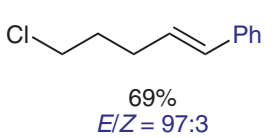

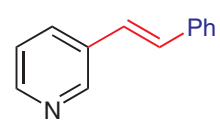

$71 \%$

$E / Z=99:$

(starting material $Z>99 \%$ )

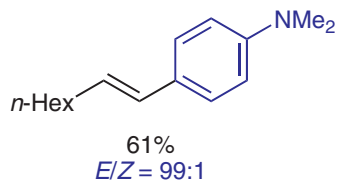

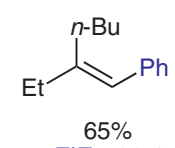

$E / Z=96: 4$ (starting material $E / Z=99: 1$ )

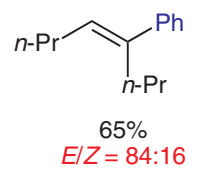

(starting material $E>99 \%$ )
Significance: In this article a highly stereoselective $\mathrm{Mn}(\mathrm{II})$-catalyzed cross-coupling reaction between (hetero)aryl Grignard reagents and nonactivated alkenyl halides is reported. The stereoinformation of the alkenyl halide is usually preserved. An exception to that rule represents the case of (Z)-3-(2-bromoethenyl)pyridine, where the configuration of the double bond is completely reversed.
Comment: This new methodology shows that also $\mathrm{Mn}$ (II) salts can be successfully used as catalysts in cross-coupling reactions with non-activated electrophiles. Mn-catalyzed reactions represent a real alternative to Fe-catalyzed reactions, since $\mathrm{Mn}$ salts are generally readily available, cheap and environmentally benign. 